Revista Docência do Ensino

Superior

v. 2, 2012

Antônio Mendes Ribeiro

UFMG

\section{MUDANDO DE CONVERSA COM AMBIENTES COLABORATIVOS DE APRENDIZADO}

\author{
Experiência com Oficinas de Blogs na Rede de Desenvolvi- \\ mento de Práticas de Ensino Superior-GIZ/UFMG
}

\section{CHANGING THE CONVERSATION IN COLLABORATIVE LEARNING ENVIRONMENTS}

\section{Experience with Blogs Workshops in the Rede de Desenvol- vimento de Práticas de Ensino Superior-GIZ/UFMG}

\title{
RESUMO
}

Este texto apresenta algumas questões básicas que estão ligadas à necessidade de maior valorização da docência de nível superior e à apropriação das Tecnologias de Informação e Comunicação TICs pelos professores interessados em inovar em suas aulas. Nele é mostrado como um professor, no papel de designer de seus cursos, pode, com o uso de blogs, criar um ambiente no qual os alunos assumam, com o seu apoio, o próprio processo de aprendizado, de forma evolutiva, aberta, conectada, contextualizada e diversificada. Descreve ao seu final um quadro de referência, que pode auxiliar na mudança de conversa nas aulas e viabilizar novos modos de participação através de diversos estágios evolutivos e crescentes, em que novos papéis são exercidos por alunos e professores, constituindo um ambiente de aprendizado colaborativo baseado nos blogs.

Palavras-Chave: Blogs. Aprendizagem com blogs. Aprendizagem colaborativa.

\section{ABSTRACT}

This paper is to answer some basic issues related to the need to view the teaching process in higher education with value and the assimilation of ICTs by teachers who are interested in innovating their pedagogical practice. It will present how a university professor, who takes the role of designer of his/her own classes can use blogs to create an innovative virtual environment to engage students in their learning process in more autonomous ways. This environment will give students the opportunity to team up, with the support of the teacher, to learn by themselves and assume more responsibility for their learning in a process that is open, connected, contextualized and diversified. It will be presented a framework that can help in the changes in the types of interactions and conversations that happen in classrooms. This will enable new forms of participation through evolutionary stages and growing at different levels, where new roles are hold by students and teachers, thus providing a virtual collaborative environment based on blogs.

Keywords: Blogs. Learning with blogs. Collaborative learning. 


\section{INTRODUÇÃO}

“Conversa é o coração desta nova era.

É talvez a habilidade humana mais fundamental para lidar com os enormes desafios que enfrentamos."

Institute for the Future

Os blogs já são usados há algum tempo em diversas áreas do conhecimento humano, em termos pessoais ou profissionais. Muitos professores, jornalistas e outros profissionais fazem uso destes com objetivos diferentes. O uso mais comum tem se constituído na forma de um "radar de notícias", captando, filtrando informações numa certa área do conhecimento e disponibilizando-as a seus leitores. Os blogs, por sua facilidade de uso e as possibilidades de autoria que propiciam, são uma boa opção para as pessoas iniciarem uma ação mais efetiva na Internet, colocando-se mais do que como um simples consumidor de informação. Com a criação de seu próprio blog, as pessoas podem estabelecer a sua identidade no espaço virtual, compartilhando conhecimentos com parceiros em função de interesses comuns. Um grande desafio existente na área de Educação é como se apropriar desse tipo de recurso como um meio de inovação do processo de ensino e aprendizagem.

Hoje, a Internet caracteriza-se por sua diversidade, com diferentes tipos de ambientes e ferramentas, com os quais uma mesma pessoa, em conexão com seus pares em comunidades virtuais, pode assumir diferentes identidades. Outra característica importante da rede é a abertura. Muitos ambientes são desenvolvidos e usados de forma livre, possibilitando que as pessoas assumam posturas diferentes, sem valorizar a hierarquia e normas rígidas. Atualmente a rede não dispõe somente de sites desenvolvidos por especialistas em tecnologias ou áreas específicas (o que caracterizava a era denominada de web 1.0 ou web dos documentos). É cada vez maior a participação das pessoas nos ambientes da rede, como blogs, wikis e redes sociais (a chamada web 2.0 ou web participativa). Tais ambientes em rede são marcados por sua contextualização, envolvendo as pessoas de acordo com problemas, informações e práticas de seu próprio interesse. Eles estão, inclusive, se aproximando cada vez mais do mundo real (a web das coisas). São ambientes ideais para uma pessoa ter autonomia e dirigir seu próprio aprendizado ou carreira profissional.

$\mathrm{Na}$ atualidade, o nosso relacionamento com o conhecimento é diferente; a maneira de gerá-lo, compartilhá-lo, construi-lo mudou. As pessoas não são somente consumidores de conhecimento, são cada vez mais autores, usando ambientes de colaboração, formando teias com seus pares. O autor George Siemens, no livro Knowing 
Knowledge (SIEMENS, 2006), salientou fatores que mostram como o trabalho com o conhecimento está mudando. Por exemplo, hoje é importante reconhecer tanto quanto conhecer, em função da abundância de informação que podemos facilmente ter acesso. Esse "pano de fundo" traz implicações muito significativas para o dia a dia, seja no serviço ou na escola.

Os desafios criados pelas mudanças na nossa sociedade e nos ambientes de trabalho fazem com que os educadores prestem mais atenção na possibilidade de criação de ambientes em que os alunos possam, de forma autônoma, compartilhar conhecimentos e colaborar com seus colegas na resolução de problemas ou no desenvolvimento de projetos de interesse comum. Essa capacidade, até então, era uma obrigação deixada por conta dos próprios alunos. Aqueles que conseguiram atingir esse nível de aprendizado, aqueles que por conta própria aprenderam como aprender, certamente tiveram mais sucesso no alcance dos níveis mais altos de sua graduação ou carreira profissional. Agora muitos professores e escolas já veem como obrigação auxiliar os alunos a tornarem-se agentes ativos e autônomos em ambientes colaborativos de aprendizagem.

Esse é mais um desafio colocado para os professores: recriar ambientes de ensino nos quais seu papel, no processo de aprendizado de seus alunos, seja mais amplo, passando de simples expositores de conteúdos (conversa unilateral) a parceiros na construção do conhecimento (conversa de muitos para muitos) de acordo com o perfil profissional que os alunos devem alcançar. A apropriação de novas tecnologias exige do professor uma nova linguagem de aprendizado, mais voltada para um diálogo reflexivo com os alunos. Independente de problemas na sua formação básica, atualmente os alunos têm um perfil cognitivo diferente, se comunicam de outra forma, são mais criativos, principalmente se tiveram condições de nascer imergidos em ambientes cada vez mais digitais (o que é uma tendência para a maioria dos alunos da universidade). Essa mudança de conversa é essencial para sobreviver às transformações que ocorrem no mundo contemporâneo, e é a base para criação de ambientes inovativos de aprendizagem voltados para a realidade das novas gerações (BARLETT-BRAGG, 2011). 


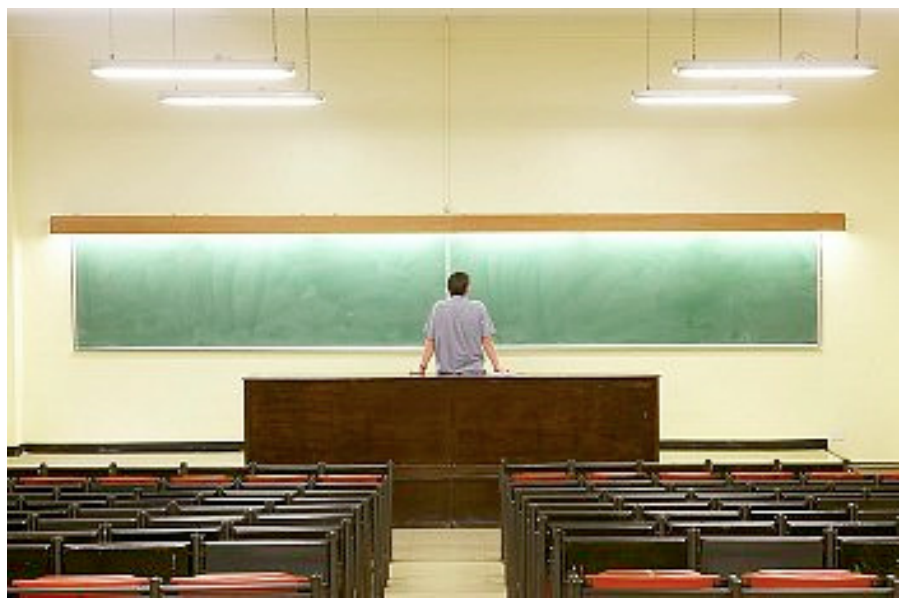

Figura 1 - O vazio das nossas salas de aula. O desafio do uso dos blogs: trazer de volta a audiência.

Esse é o contexto no qual se baseia este texto, que procura responder algumas questões básicas, mostrando os propiciamentos das tecnologias e as possibilidades de apropriação dos ambientes de colaboração, em especial dos blogs, por professores de ensino superior e seus alunos. Os próximos itens mostram mais detalhadamente diversas maneiras de uso dos blogs nas aulas e como a expansão e diversidade da Internet estão impactando essa possibilidade. Além disso, são discutidas as barreiras vivenciadas pelos professores na apropriação das tecnologias que podem promover a inovação na sua prática docente. Nesse sentido, é importante citar a experiência da Rede de Desenvolvimento de Práticas de Ensino Superior - GIZ/UFMG na oferta de oficinas de blogs, tendo-se observado com clareza o distanciamento que um professor universitário típico tem do uso das tecnologias e em especial dos blogs, no que se refere às necessárias mudanças de sua prática junto a seus alunos. A visão existente sobre as possibilidades e necessidade de mudança certamente impede a adequação das aulas a uma melhor educação demandada pela realidade atual do nosso país ou até mesmo servem para justificar possíveis omissões nesse sentido. É abordada, ainda, a forma de criação de ambientes colaborativos de aprendizado com o uso das tecnologias disponíveis. No caso específico dos blogs, propõe-se um quadro de referência que pode ajudar no design de um processo evolutivo de participação dos envolvidos (professores e alunos), descrevendo os fatores significativos que permitem a viabilização desse desafio.

Quadro 1- Questões básicas trabalhadas neste texto

- As pessoas trabalham com o conhecimento hoje da mesma forma que alguns anos atrás?

- Ainda é importante contar histórias durante as aulas, inclusive com o uso das TICs?

- Quais são as características e o potencial de uso dos blogs no contexto dos ambi- 
entes de colaboração da atual era da Internet?

- O uso das tecnologias no processo educacional de hoje é a única barreira que um professor enfrenta para inovar nas suas aulas?

- Quais os novos papéis em relação ao processo de ensino e aprendizado que um professor deve assumir atualmente, além do que ele vem exercendo desde a antiguidade: expositor de conteúdos?

- Como normalmente os professores reagem às mudanças que ocorrem na nossa sociedade (perfil dos alunos, explosão das TICs, maior valorização do social, demanda do mercado de trabalho global)?

- Como os blogs podem ser apropriados no processo de ensino e aprendizado de nível superior?

\section{CONTANDO HISTÓRIAS COM OS BLOGS}

"Eu somente sei uma coisa acerca das tecnologias que nos aguardam no futuro: acharemos meios de contar histórias com elas." Jason Ohler

O professor Steve Wheeler, da Faculdade de Saúde, Educação e Sociedade da University of Plymouth, Inglaterra, além das suas publicações acadêmicas convencionais, dispõe de um blog (WHEELER, 2011), onde lança novas ideias e as valida junto a seus leitores. Com sua experiência como professor universitário blogueiro ele nos dá boas razões para que se reflitam sobre as possibilidades do uso de blogs na prática de ensino e aprendizado. De acordo com o citado professor, na medida em que se escrevem textos, criam-se significados concretos de ideias abstratas. Como os blogs são públicos, escreve-se para uma audiência. Escrever torna-se um ato social e, ao conhecer melhor nossos pensamentos, é possível compartilhá-los com as outras pessoas. É uma reflexividade em ação, para o autor e seus leitores: criação, reflexão e refinamento do pensar.

Quadro 2 - Razões para se ter ou não ter um blog (WEELER, 2011)

7 boas razões pelas quais você, como um professor, deve ter seu blog ( segundo o professor Steve Weeler):

- Faz com que você reflita sobre a sua prática.

- Permite a cristalização de seu pensamento: ao se compor e recompor ideias, faz com que pensamentos, no início mais abstratos, tornem-se concretos.

- Permite a criação de novas audiências além de sua sala de aula.

- $\quad$ Pode criar um momentum pessoal, quebrando a sua inércia em especial nos as- 
suntos de fronteira, emotivos, controversos ou desafiadores.

- Pode proporcionar uma realimentação valiosa de seus leitores, que lhe permita a consolidação ou mudança de suas ideias.

- Pode ser um ato criativo, permitindo a descoberta de maneiras novas e inovativas de articular suas ideias.

- Permite a ampliação de seu jogo, num ambiente global, com uma audiência que responde de forma imediata às suas ideias.

Do mesmo professor: as principais razões que levam a um professor a não blogar (todas elas normalmente verdadeiras):

- Receio de se expor em público, de não conseguir colocar ideias marcantes ou inovativas de interesse dos demais.

- Na sua escola não existe o acesso ou o apoio ao uso dos recursos necessários.

- Acredita que não tem tempo para se dedicar a essa atividade, vive sobrecarregado com múltiplas tarefas.

\section{Porém, a maior razão certamente é:}

- Desconhece ou não tem condições de saber os reais benefícios que os blogs podem oferecer à sua própria pessoa.

Esse tipo de processo dialético se parece mais com debates ou com o processo de contar histórias, em que cada um, ao repassá-las, insere a sua versão, acrescentando novas nuances ou peculiaridades. Sínteses de ideias podem ocorrer mais rapidamente para quem está envolvido, e mesmo para aqueles que participam de forma periférica e somente observam. Segundo o professor Wheeler, há muitas razões para blogar e muito mais razões para fazê-lo regularmente, principalmente para quem está envolvido com educação. O que ele preconiza é a ressurreição e expansão no mundo digital de uma prática que existe desde que o homem existe, ou seja, contar histórias.

Os contadores de histórias moldaram a sociedade e sua maneira de pensar. As histórias são usadas para o entretenimento, o ensino, a transmissão de conhecimentos, seja em volta da fogueira, como antigamente, ou em volta da tela do computador, como atualmente. No início, só se podia contar histórias usando a mídia oral. Na préhistória, o conhecimento era transmitido de boca em boca, do mestre para os aprendizes, de pai para filho. Quando se queria transmitir um conhecimento, tinha-se que contar histórias: criar um ambiente propício com grupos em volta da fogueira, aumentar a motivação, usando-se de danças, cantos ou gestos. Com o passar do tempo, foi possível se usar a escrita, depois o audiovisual, sendo agora possível se contar histórias multimídias e digitais, receber todo dia dos amigos, colegas e mesmo de desconhecidos, al- 
guns ainda usando e-mails, pequenas histórias contadas e recontadas nos seus blogs ou redes sociais, normalmente ilustradas por imagens, áudios e vídeos (BRYAN, LEVINE, 2008).

Ao se conectar na rede, pode-se ver contadores de casos expondo aos parceiros suas pequenas histórias, conversas ou narrativas com conteúdos digitais multimídia. Tem-se um ambiente de contar histórias de forma colaborativa, a muitas vozes e estilos diferentes, muitas vezes sem início e fim, normalmente não lineares (agora não começam mais com: "era uma vez..." e terminam com: “..viveram felizes para sempre").

\section{CONHECENDO MELHOR OS BLOGS}

"A minha presença online é baseada em blogs, escritos e cursos. O que o Twitter e o Facebook fizeram para mim? Na realidade nada. Eles são bons para atividades baseadas em eventos. A substância necessita existir além disso." George Siemens

Os ambientes de colaboração, como os blogs, são um novo canal de comunicação para os contadores de casos do século XXI, em que, da mesma forma que na pré-história, pode-se fazer uso de metáforas, mitos, parábolas ou fábulas (agora de forma interativa e multimídia e mesmo mais rápida e fragmentada) para manter a atenção e o engajamento dos participantes. Além disso, é possível se fazer uso de vários tipos de ambientes de colaboração além dos blogs, como fóruns, wikis e redes sociais, cada um com suas características ou propiciamentos próprios. A escolha de qual desses recursos utilizar vai depender dos nossos objetivos e do perfil dos envolvidos. A utilização também pode ocorrer de diversas formas e níveis, em função de fatores tais como o controle que é exercido no ambiente, o nível de conhecimento que o ambiente criado permitirá que seus participantes alcancem, assim como o nível de seu envolvimento na interação entre estes. Esses são fatores inter-relacionados, por exemplo, em ambientes mais abertos, como comunidades de aprendizado: na medida em que a colaboração é exercida, ela tende a favorecer o crescimento de criatividade.

No caso dos blogs, pode-se definir resumidamente suas principais características.

Controle exercido no ambiente: normalmente pessoal e centralizado num autor. Este permite ou não que seus leitores façam comentários sobre suas postagens. Há casos de blogs sob o domínio completo de seus autores. Noutros casos tem-se, por 
exemplo, professores ou os próprios alunos que concedem parte desse controle a grupos mais fechados (turma do curso) ou a comunidades abertas (público em geral).

Estrutura do ambiente: linear de forma cronológica inversa. O que se vê são as postagens mais novas, as mais antigas desaparecem com o tempo, apesar de ficarem todas armazenadas. O responsável pelo blog deve prover mecanismos adequados para os leitores navegarem e terem acesso às informações do ambiente (índices, tags). A organização de postagens e comentários é pré-definida. Isso se contrapõe aos wikis, cuja organização, atualização e reorganização dos conteúdos pode ser feita de forma mais fácil e colaborativa.

Interação com o usuário do ambiente: como uma mídia digital, os blogs permitem interações públicas de um autor com seus diversos leitores. Alguns desses autores preferem criar um ambiente unidirecional, não permitindo que seus usuários façam comentários. A interação possível normalmente nos blogs (um para muitos e multidirecional) não é tão ampla como nas redes sociais (nas quais a interação é de muitos para muitos em ambos os sentidos), porém essa restrição tem fatores positivos que podem ser aproveitados em ambientes educacionais (fortalecimento da presença do professor ou do autor).

Tipo de informação disponibilizada no ambiente: blogs normalmente são mais centrados na publicação de conteúdos em páginas multimídia independentes (postagens), por possibilitar edição fácil, sem necessidade de conhecimentos especializados. Por outro lado, também permite a realização de diálogos, através de comentários às postagens existentes.

Modos de conversa que podem ocorrer no ambiente: os blogs normalmente são vistos como ambientes em que um autor pode disponibilizar suas histórias, narrações, exposições ou relatos de complexidade média (tamanho, dinâmica). Porém, a riqueza dos blogs não está em monólogos, mas na possibilidade de criação de diálogos reflexivos centrados nas postagens existentes. Um autor pode receber o retorno de seus leitores e sustentar uma conversa enriquecedora com a troca de comentários, na forma de complementações, resumos, sugestões e recomendações (HALIC, 2010). O blog não é um meio de comunicação adequado para mensagens, avisos, recados rápidos a serem trocados entre duas pessoas ou grupos de amigos (nesse caso, o ideal será o e-mail, os microblogs). Da mesma forma, não é adequado a diálogos ou conversas mais rápidas e superficiais, que não exigem grande reflexão, como é o caso que normalmente ocorre nas conversas de redes sociais. Na medida em que se fica perdido no dilúvio de infor- 
mações das redes sociais, os blogs atuam como a Arca de Noé, por permitir que se faça uma síntese do que está ocorrendo e, assim, sobreviver através de um processo de compartilhamento de entendimento.

Nível de envolvimento no ambiente: o grau de envolvimento dos participantes de um ambiente baseado nos blogs tende a se restringir a simples contribuições isoladas e ocasionais, em que as pessoas colocam informações descontextualizadas, de todo tipo, sem considerar o perfil do leitor existente e suas necessidades. Uma ação mais direcionada do autor do blog pode elevar o nível de participação, na medida em que torne claros os objetivos existentes, o tipo de audiência a que se destina e disponibilize sistematicamente informações atualizadas e de interesse desta. Avançar mais o nível de participação é um desafio, uma vez que se trata de um esforço significativo que deve envolver o autor e a sua audiência. É o caso da criação de ambientes colaborativos de aprendizado, no qual o professor e os alunos necessitam mudar seus papéis e posturas normalmente existentes e arraigadas há muito tempo na cultura vigente das conversas unidirecionais e autoritárias.

Nível de conhecimento possível de ser alcançado: os blogs não devem se restringir à disponibilização de publicações que facilitem a simples assimilação de informações (apesar de livros no formato pdf, vídeos e músicas poderem fazer parte das suas postagens). Um blog pressupõe conversas, leituras, o que exige um maior nível de entendimento das informações disponibilizadas e dos diálogos que possam ocorrer. Os blogs são mais propícios à criação de ambientes de reflexão em que as pessoas recebem as novas informações, fazem relações com o que já conhecem e constroem novos conhecimentos. O papel de um professor está em criar um ambiente em que a criatividade e inovação sejam a base da conversa existente. A integração dos blogs criados pelos alunos com os demais existentes na rede, o envolvimento na blogosfera, permitirá o acesso a visões diferentes, a novas práticas de especialistas de áreas de interesse que trabalhem em laboratórios avançados de pesquisa ou em empresas de desenvolvimento de ponta. Com isso, os alunos podem validar de forma contextualizada os conhecimentos construídos no curso. Esse é um nível que pode ser alcançado, com muito esforço e determinação, num curso da Universidade, integrando de forma positiva atividades de ensino, pesquisa e extensão.

Intenção de uso: veem-se várias formas de apropriação dos blogs em função dos objetivos de seus autores ou leitores, pois eles são cada vez mais reconhecidos co- 
mo um ambiente social e não somente uma nova mídia de comunicação. Pode-se salientar:

- Jornal de Informações (publicação sistemática de notícias, pequenos artigos de assuntos técnicos ou acadêmicos). O foco é o conteúdo.

- Radar de Notícias (seleção, agregação automática, curadoria de notícias sobre um tema específico). O foco é a novidade.

- Ambiente Colaborativo de Aprendizado (favorecimento de reflexão, senso de comunidade e compartilhamento de conhecimento num processo de construtivismo colaborativo). O foco é a colaboração.

- ePortfolio (registro ao longo da vida da experiência profissional ou escolar de uma pessoa interessada em alcançar níveis mais avançados nas suas áreas de atuação). O foco é o envolvimento no mercado de trabalho ou no processo de aprendizado.

- Ambiente Pessoal de Aprendizado / PLE - Personal Learning Environment (organização centralizada dos recursos de um aprendiz: ferramentas, conteúdos, tarefas a realizar, avaliações, ambientes de colaboração dos quais participa). O foco são os recursos para o aprendizado.

Todos esses modos de utilização dos blogs podem ser adotados nas práticas de ensino superior, com controle centrado no professor (como um jornal de notícias sobre os avanços e inovações da sua área ou mesmo tutoriais), centrado em grupos de alunos (um ambiente colaborativo de aprendizado) ou numa comunidade (como um radar de notícias numa rede social sob responsabilidade de uma turma de alunos). Nos itens seguintes deste texto, é mostrado como viabilizar a participação de alunos num ambiente colaborativo de aprendizado, no qual possam se engajar em conversações através de blogs com o objetivo de construir de forma autônoma significados, compartilhando-os com os colegas e validando entendimentos obtidos. Isso será possível de ser alcançado na medida em que os professores ajam como designers desses ambientes e como facilitadores do aprendizado na realização das atividades pelos alunos.

Hoje, a utilização de blogs tende a diminuir, já que menos pessoas têm se aventurado na criação dessa mídia. Isso se deve a vários fatores. As mais centradas em conteúdos ainda se sentem melhor postando nos blogs (Blogger). Outras preferem usar um ambiente que acabou de ser lançado (Google+), o qual está na moda. Nas redes sociais, como no Facebook, as pessoas ficam mais à vontade mandando mensagens sim- 
ples com no máximo uma mídia anexada. Outras preferem agir em tempo real, acessando os microblogs (Twitter), respondendo na hora, na medida em que os fatos ocorrem. A grande diversidade de ambientes de colaboração é um fato na era atual da Internet. Algumas redes sociais disponibilizam ao mesmo tempo diversos recursos, como páginas, fóruns, blogs, mensagens aos participantes (Ning). A tendência é que os seus usuários vivenciem, ao mesmo tempo, esses vários espaços, não necessariamente com a mesma identidade. Em função dessa diversidade, os professores têm um problema adicional: definir qual desses ambientes é mais adequado para ser utilizado em certo tipo de atividade de aprendizado.

\section{BARREIRAS NO USO DE BLOGS NA PRÁTICA DOCENTE}

"O conhecimento não se destina a encher as mentes, mas a abri-las." George Siemens

Apesar do desenvolvimento tecnológico existente e do grande potencial que as tecnologias têm como um meio de inovação no ensino e aprendizado, muito pouco se tem visto nessa área nas escolas, em especial nas universidades. Para a grande maioria das pessoas, em especial os professores, existe um abismo tecnológico, o que as impede de se apropriarem desses recursos em função da realidade e das necessidades de seus alunos (ELGORT, 2005).

Considerando que as tecnologias são somente um recurso de mediação para auxiliar o ensino ou o aprendizado, os que conseguem ultrapassar a barreira tecnológica ainda devem se preparar para ultrapassar um abismo pedagógico. Os recursos atualmente disponíveis na Internet têm um potencial de utilização muito grande no aprendizado, porém, não são normalmente compatíveis com as práticas convencionais de ensino (aulas expositivas, materiais estáticos e fechados, sequências pré-definidas de tarefas, avaliações através de provas formais). Há a necessidade de se apropriarem das tecnologias e avaliarem novas pedagogias, mais voltadas para ação, reflexão, abstração e experimentação a serem desenvolvidas pelos próprios alunos. As tecnologias podem ser vistas mais como um agente das mudanças pedagógicas, pois permitem a viabilização das transformações necessárias no processo educativo vigente. Urge retirar os alunos do vazio que se transformaram as salas de aula nos dias de hoje. O desa- 
fio é o de como fazer isso integrando, de forma adequada, as tecnologias e as pedagogias.

$\mathrm{Na}$ verdade, as barreiras não param por aí. Enquanto a sociedade sofre um processo crescente e rápido de mudanças, as práticas e os processos de trabalho nas empresas estão se adaptando à essa nova realidade. Algumas profissões estão sofrendo mudanças radicais, como, por exemplo, na área de marketing. As empresas não se relacionam com os consumidores da mesma forma como alguns anos atrás. Na prática, estes é que divulgam e aconselham os produtos ou serviços a seus amigos ou demais participantes das redes sociais. Isso exige dos profissionais dessa área novas posturas e formas de trabalho. Apropriar-se das tecnologias existentes e usá-las baseadas em pedagogias adequadas não é o suficiente para formar um profissional com o perfil necessário. Assim, pode-se considerar a existência de um abismo para o alcance das competências que permitam aos alunos a sua inserção no mercado de trabalho.

Quando um professor decide utilizar um blog nas suas aulas esses abismos certamente estarão presentes. Em tese, é de se esperar que as tecnologias serão o menor desafio, pois os blogs foram criados com o intuito de permitir às pessoas com pouca experiência publicarem suas postagens sem grandes conhecimentos das tecnologias. $\mathrm{Na}$ prática, isso nem sempre é verdade. No que se refere à escolha da visão pedagógica necessária para permitir o uso adequado dos blogs, o problema é mais complexo. A par das restrições que normalmente os professores têm em investir nessa área, soma-se a visão que estes possam ter em relação aos blogs. Muitos não consideram essa mídia adequada a um ambiente acadêmico, preferindo opções mais formais, fechadas e centralizadas, sobre as quais eles possam exercer maior controle.

\section{O DESIGN DE AMBIENTES COLABORATIVOS DE APRENDIZADO}

\section{"Nunca penso no futuro, ele chega rápido demais." Albert Einstein}

Para a implementação das mudanças na sua prática de ensino, de forma a adequá-la às necessidades de seus alunos, os professores enfrentarão a necessidade de projetar ou reorganizar o seu curso (fazer o design do seu processo de aprendizado e ensino). As teorias mais atuais salientam que fatores sociais e culturais devem ser considerados para explicar o aprendizado e desenvolver novas abordagens pedagógicas (CONOLE, 2011). Aprendizado não é somente um problema cognitivo, mas também um processo 
de participação em grupos ou comunidades envolvendo práticas colaborativas, com co-criação de conhecimento e valores. O design pedagógico dos espaços em rede e colaborativos deve ser mais indireto, na forma de um andaime (scaffold) de aprendizado, focado nas experiências definidas pelos próprios aprendizes, sem a determinação causal dos resultados a alcançar (VYGOTSKY,1998).

Para se avançar além do chamado "design instrucional" clássico, pode-se adotar algumas estratégias como as descritas adiante, que propõem avanços em termos do aprendizado colaborativo em redes. É possível oferecer suporte aos alunos de forma distribuída (scaffolding distribuído) e complementar, utilizando as diversas ferramentas e envolvendo, no processo, tutores, especialistas e os próprios pares, quando houver necessidade, até que os aprendizes alcancem os objetivos desejados. Em vez de serem colocados a priori, algum tipo de suporte pode ser disponibilizado ao longo do processo (em função das necessidades dos alunos), como arranjamentos sociais, gabaritos, esquemas gerais de resolução de problemas, intervenções do professor.

Os ambientes de aprendizado colaborativos em rede devem ser realizados através de design indireto (LAKKALA, 2007). Devem prover estruturas básicas de suporte, as quais possam oferecer propiciamentos que permitam a realização de atividades de aprendizado escolhidas pelos próprios aprendizes, sem que sejam prescritas de forma precisa, assim como seus resultados. Como as pessoas precisam, no seu dia a dia, de uma infraestrutura básica (espaços, estruturas, tecnologias), no design dos ambientes colaborativos de aprendizagem é necessário criar uma infraestrutura pedagógica adequada, em que devem ser considerados os aspectos técnicos, sociais, epistemológicos e cognitivos. Além da necessidade da infraestrutura técnica (espaços físicos, tecnologias e ferramentas necessárias) e uma infraestrutura social (como a colaboração é organizada e suportada) esses ambientes necessitam de uma infraestrutura epistemológica (a base para que o conhecimento seja construído, entendido, compartilhado e aplicado). Isso é mais do que ensinar certo assunto a partir de conteúdos colocados na forma, por exemplo, de um tutorial ou simples pesquisas baseadas em problemas existentes. Esta infraestrutura permite criar as condições para que o conhecimento seja o objeto essencial do trabalho dos aprendizes em desenvolvimentos colaborativos.

Faz parte também do design de um ambiente de colaboração a criação de uma infraestrutura cognitiva que propicie aos alunos o entendimento consciente de suas próprias estratégias de aprendizado, permitindo que, gradativamente, aprendam a trabalhar de forma autônoma. Essa é uma postura essencial na sociedade atual. O de- 
sign pode favorecer o desenvolvimento de um novo papel no processo de aprendizado por parte do aluno, tornando o processo visível para o mesmo (uso de modelos, como mapas mentais) e promovendo, de forma deliberada, auto-avaliação reflexiva (DU, 2005).

Assim, caso um professor decida utilizar em suas aulas um ambiente colaborativo de aprendizado baseado em blogs, devererá elaborar o design deste provendo as seguintes infraestruturas pedagógicas:

Infraestrutura Técnica: os blogs são considerados um meio próprio para as pessoas leigas em informática, pois não exigem altos conhecimentos e recursos técnicos na sua criação e utilização. Muitos alunos já têm acesso a esses conhecimentos desde crianças, nas suas explorações das redes sociais. Para se iniciar nessa área, é preciso ter um computador pessoal ou laboratórios de informática ligados à Internet, o que a maioria das escolas já disponibiliza. Algumas instituições preferem instalar software de blogs em servidores próprios (Wordpress) em vez de usar os que são disponibilizados de forma pública (Blogger). De qualquer maneira, é sempre necessária a disponibilização de um suporte técnico e de apoio no uso das funcionalidades mais especializadas dos blogs (widgets, configuração), o que pode ser promovido com o envolvimento dos próprios alunos. Hoje nos blogs é possível agregar pequenas aplicações (widgets ou gadgets) que ampliam a experiência de seus usuários. Com isso os alunos podem trazer para o ambiente, por exemplo, ferramentas de trabalho, consolidando a sua blogosfera, com interligação entre seu blog e os de seus colegas.

Nos blogs pode-se colocar postagens multimídias que permitem estabelecer várias formas de intermediação entre o professor, ao ensinar, e o aluno, ao aprender. A autora Diana Laurillard, no seu livro Rethinking University Teaching (LAURILLARD, 2002), afirma que cada tipo de mídia tem propiciamentos diferentes adequados a diferentes experiências de aprendizado. Mídias narrativas (textos, apresentações eletrônicas) dizem ou mostram alguma coisa. Mídias interativas (pesquisadores, testes de múltipla escolha) respondem de forma limitada ao que o aluno faz. As comunicativas (e-mail, microblogs) facilitam o intercâmbio entre pessoas. Mídias adaptativas (jogos, simulações) mudam em função do que o aluno faz. As produtivas (editores de texto, planilhas) permitem que o aluno produza alguma coisa. Atualmente é possível reconhecer mais um tipo de mídia, as sociais (blogs, redes sociais) que propiciam o envolvimento de pessoas em grupos ou comunidades em função de um interesse comum. Para cada curso, a infraestrutura técnica será diferente, podendo-se deixar por conta do 
próprio aluno estabelecer o seu Ambiente Pessoal de Aprendizado (WILSON, LIBER, JONHSON, BEAUVOIR, SHARPLES, MILLIGAN, 2006). Nesse tipo de ambiente, o próprio aluno organiza as ferramentas e ambientes de colaboração a utilizar, em decorrência de suas necessidades.

Infraestrutura Cognitiva: mesmo com a grande diversidade de ferramentas e ambientes sociais existentes na rede, os blogs podem se constituir num espaço efetivo de exploração, construção, resolução e confirmação do entendimento através de colaboração e reflexão envolvendo alunos e seus professores. A publicação fácil, com postagens e comentários para uma audiência contextualizada, são fatores efetivos para a criação de comunidades de aprendizado. Os blogs podem se constituir em um ambiente em que os professores coloquem questões ou problemas que despertem a curiosidade e o envolvimento dos seus alunos, permitindo que estes assumam sua identidade na rede, adquirindo senso de comunidade. $\mathrm{O}$ acesso e a incorporação (sharing) de fontes de conteúdos multimídia nas postagens podem dar subsídio às discussões e favorecer o encontro de respostas, o entendimento dos conceitos fundamentais das aulas e a solução dos problemas colocados. Na literatura pode-se encontrar um quadro de referência voltado para a criação de comunidades de inquirição (Community of Inquiry Framework), que, baseado em pesquisas e práticas, nos oferece estratégias para viabilização desse tipo de infraestrutura pedagógica.

Para o estabelecimento da infraestrutura cognitiva, o professor D. R. Garrison da Universidade de Calgary (GARRISSON, 2007) oferece um quadro de referência que pode ser útil. É conhecido como o framework de uma comunidade de inquirição, que tem sido muito usado na pesquisa e no estudo da presença do social, do cognitivo e do ensino na avaliação e realização de comunidades online de aprendizado colaborativo. A presença cognitiva é definida como exploração, construção, resolução e confirmação do entendimento através de colaboração e reflexão. Em princípio, pode ser estabelecida através de um ciclo de inquirição, em que os participantes se envolvem de forma deliberada, para permitir o entendimento de um problema ou questão, a partir de um evento de disparo, que os desafia a iniciar uma experiência de auto-direcionamento de seu próprio aprendizado. Nesse processo, a partir da percepção (conscientização) do problema, os alunos avançam, em termos da exploração pessoal, levantando e trocando informações ou alternativas pertinentes para ajudá-los no seu entendimento do problema. A partir das ideias formuladas nessa fase, os alunos estarão aptos a construir significados, fazendo sua integração, ligando os conceitos de forma crítica, o que 
possibilitará o alcance de soluções. De forma deliberada, são capazes de aplicar as ideias exploradas, construindo suas próprias ideias (concepções). Numa fase final de resolução, eles são capazes de aplicar os conhecimentos adquiridos, co-construí-los em ação, validando-os na prática de conversações junto a parceiros.

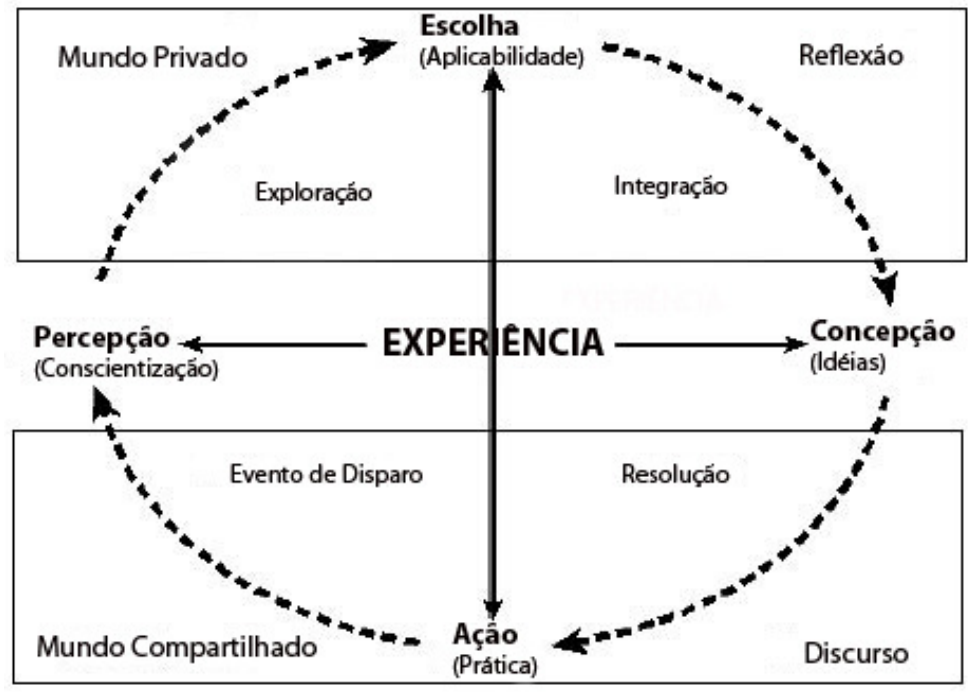

Figura 1 - Modelo do processo de inquirição (GARRISON, 2007)

Infraestrutura Social: a presença do cognitivo em si não é suficiente para garantir o aprendizado (mesmo que seja o foco deste), necessitando do auxílio de uma infraestrutura social que envolva facilitadores do processo de aprendizado (aluno, seus pares, professor). Os blogs, como um ambiente de colaboração, podem auxiliar nesse sentido, apesar de terem uma estrutura linear e sequencial. Por outro lado, a sua simplicidade, a abertura e mesmo o controle mais centralizado são fatores significativos para engajar os alunos de forma autônoma. As colocações nos blogs, os comentários que forem resultado das discussões organizadas pelo professor, podem envolver, de forma crescente, os alunos num processo reflexivo, criando senso de grupo ou comunidade, com o qual se sintam social e emocionalmente ligados. Esses diálogos se constituirão em uma mídia rica, que além de servir de material de estudo, pode servir de exemplo para as próximas turmas se encorajarem a entrar nas discussões, vencendo as barreiras que naturalmente existem para os alunos acostumados a participar de forma passiva nas aulas convencionais. Na atual era da internet é possível integrar os professores e alunos com o uso de diversos ambientes de colaboração existentes na rede. Pode ser usada comunicação rápida através de mensagens curtas (Twitter), escolher pares a trabalhar (Google+), trocar notícias (Facebook), validar conteúdos mais elaborados (blog) ou construir conhecimento de forma coletiva (wiki). 
Baseando-se no livro E-tivities da autora Gilly Salmon (SALMON, 2002), é possível definir um conjunto de estágios de participação pelos quais uma pessoa, de forma evolutiva, deve passar para vencer os obstáculos existentes, explorando o potencial que as tecnologias da informação oferecem na atualidade.

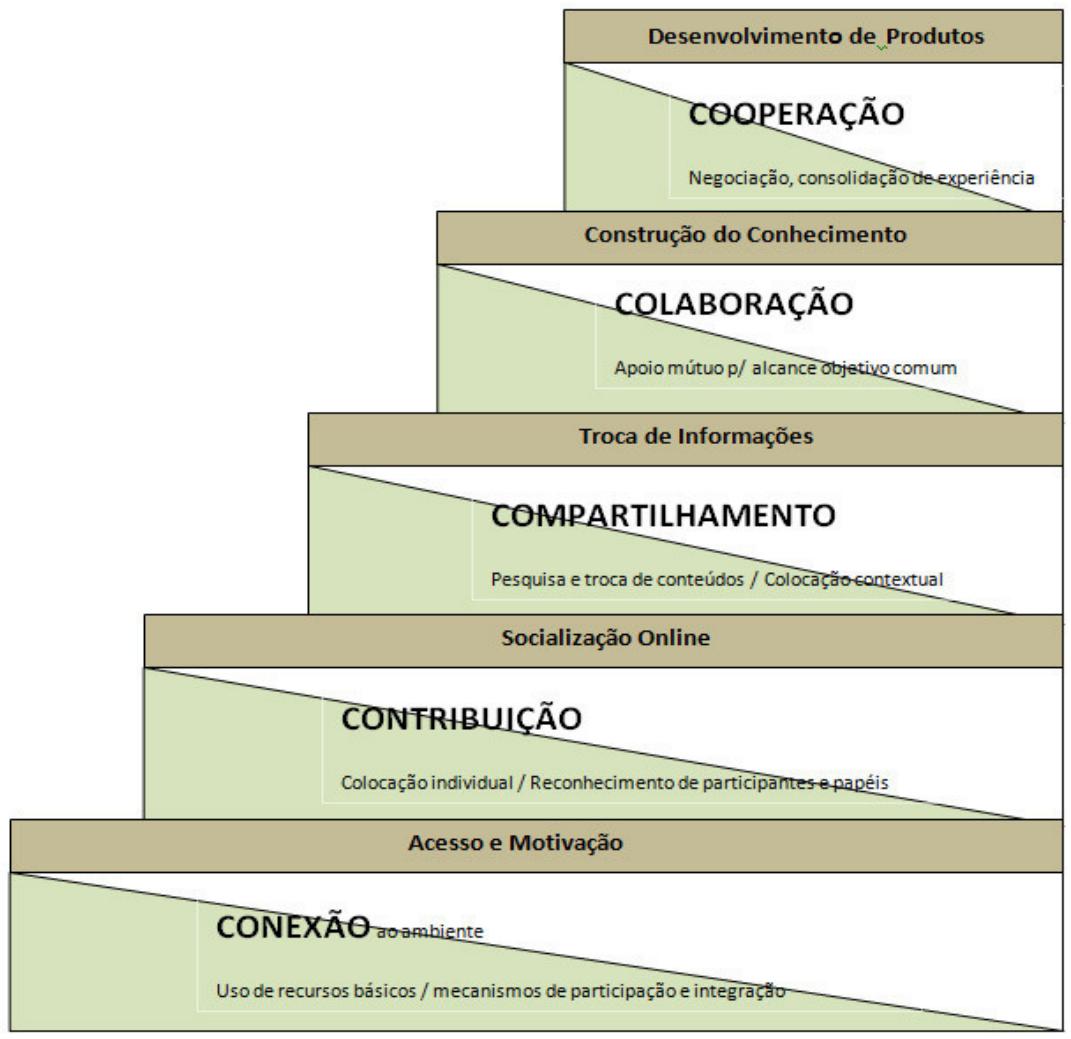

Fig 2 - Evolução da participação nos ambientes sociais da rede

O primeiro passo, conexão, é o momento inicial em que se criam as condições para o acesso de usuários ao sistema em que se quer participar e criar motivação para continuar. O estágio de contribuição é aquele em que os indivíduos iniciam a sua sociabilização, o que permite o início de uma participação mais ampla, em que se cria a identidade pessoal e a liberdade de agir no ambiente. Já no estágio de compartilhamento, é iniciada a identidade coletiva, o que é mais fácil de ser alcançado em grupos formais, contribuindo com conteúdos e iniciando os diálogos de forma contextualizada. Na fase de colaboração, os participantes assumem uma postura de ajuda mútua, em comunidades, auxiliando os demais a alcançar seus objetivos. No estágio de cooperação, o comprometimento é maior e o alcance dos objetivos não é problema somente dos outros, afetando a todos pessoalmente. É quando se desenvolve, com parceiros da comunidade, produtos ou práticas mais formais e definidas, importantes para ao alcance dos objetivos ou a evolução da comunidade. 
Infraestrutura epistemológica: os recursos da rede permitem hoje que se trabalhe com o conhecimento para a tomada de decisões ou resolução de problemas de uma forma aberta, distribuída e contextualizada. Criar conhecimento não é mais um privilégio dos professores ou de especialistas em certo domínio. Os blogs têm um papel muito significativo nesse sentido, pois privilegiam o autor e permitem a publicação de conteúdos multimídia. Além disso, permitem, através dos comentários, a coconstrução e o compartilhamento do conhecimento num processo crescente de construção, envolvendo vários participantes na forma de grupos ou comunidades. O conhecimento nesse tipo de ambiente pode ser concretizado de várias formas, com a utilização de multimídias (texto, áudio, vídeo, imagens, mapas mentais). São ambientes nos quais se pode criar e sustentar uma cultura de questionamento crítico e compatível com a realidade dos seus participantes.

É possível reconhecer que, ao se construir conhecimento num ambiente de colaboração em rede, pode-se atingir quatro níveis: sequencial, relacional, criativo e conectando.

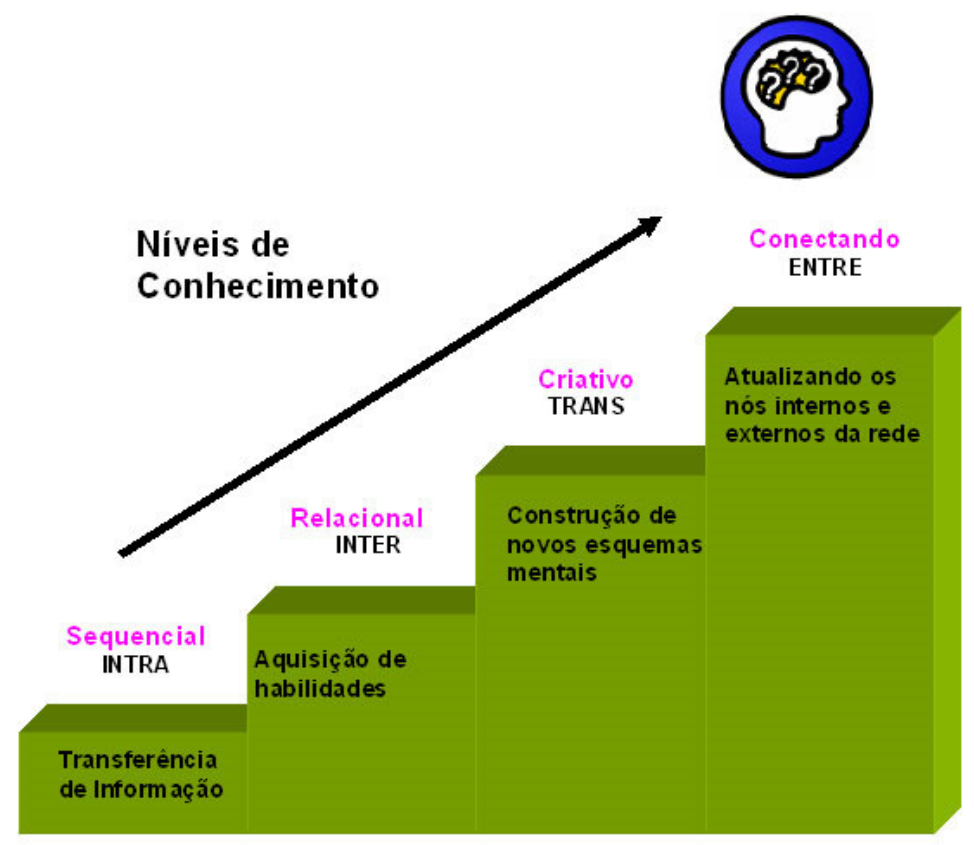

Figura 3 - Níveis de construção do conhecimento em rede (RIBEIRO, COELHO, 2006)

O sequencial corresponde à assimilação simples de um conteúdo na medida em que uma pessoa tenha motivação para tal. Quando o professor expõe uma matéria pela primeira vez, apresentando o objeto de aprendizagem aos alunos, estes adquirem inicialmente esse nível de conhecimento, obtido por transferência de informação. Nes- 
se ponto, os alunos ainda não têm pleno domínio do assunto, não sendo capazes de relacionar os conceitos ou fatos assimilados com outros conhecimentos que já possuem, ou mesmo de criar novos conhecimentos. Num segundo momento, eles conseguem alcançar o nível relacional, centrado no indivíduo, quando ele é capaz de interagir os novos esquemas mentais com os já existentes e, com isso, ampliar o seu conhecimento por aquisição de novas habilidades mentais. Já no terceiro nível, o criativo, com base nos níveis anteriores existentes, ele pode construir novos esquemas mentais, sendo capaz de fazê-lo em colaboração com seus pares. A compreensão da totalidade do objeto do conhecimento somente será alcançada no quarto nível, o conectando, fazendo conexões e re-conexões, externas e internas, sendo capaz de referendar o conhecimento construído anteriormente numa rede de cooperação entre parceiros, em que pode aplicar e validar seus saberes (RIBEIRO, COELHO, 2006).

\title{
6. A VIABILIDADE DO USO DE BLOGS NO PROCESSO DE APRENDIZADO E ENSINO DA UNIVERSIDADE
}

\author{
"Os problemas significativos que enfrentamos \\ não podem ser resolvidos no mesmo nível de pensamento \\ em que estávamos quando os criamos." \\ Albert Einstein
}

Esforços como a criação de uma Rede de Desenvolvimento de Práticas de Ensino Superior - GIZ pela UFMG (GIZ, 2011) justificam-se em decorrência da necessidade de se valorizar o papel de docente na prática da Universidade. Nesse contexto, inclui-se a capacitação dos professores com o objetivo de se tornarem designers de sua própria prática docente, o que corresponde a um desafio significativo na mudança de seu papel e de seu modo de atuação nas suas conversas de ensino e aprendizado até então adotadas. O autor Peter Goodyear, da Universidade de Sydney, Austrália, em relatório final de projeto para o Australian Learning and Teaching Council (GOODYEAR, 2009), salienta os principais fatores que ocorrem em praticamente todas as partes do mundo, e que pressionam os professores para que se envolvam nas mudanças necessárias. Como normalmente os professores não são preparados para enfrentar esses desafios, num primeiro momento apelam para soluções paliativas e não inovadoras, que não consideram a raiz dos problemas existentes.

O envolvimento de maior número de alunos nas universidades está introduzindo, nesse meio, maior diversidade de necessidades, expectativas e previsões. Esse não é um problema somente do país, ocorrendo no mundo inteiro. Além disso, os em- 
pregadores não estão satisfeitos com o perfil dos alunos recém-graduados, os quais não têm demonstrado capacidade para enfrentar as incertezas e os desafios do novo mundo. A aceleração das mudanças tecnológicas e a necessidade crescente de acesso e adequada apropriação destas, acentuam o abismo existente para as competências que o mercado de trabalho exige, o que reforça a necessidade da criação de ambientes educacionais de valor, alinhados a pedagogias compatíveis com a nova realidade. Por outro lado, enquanto o número de alunos por docente se amplia, os professores têm atualmente uma demanda crescente do seu tempo e energia intelectual, o que os tem levado a se concentrarem mais em atividades de pesquisa e desenvolvimento.

Segundo o professor Goodyear, a mudança de uma educação de elite para uma educação de massa é inexorável, preocupa a todos e deve ser acompanhada por uma maior flexibilidade e sensibilidade em função das necessidades mutantes dos alunos. Investir na capacidade dos professores como designers de aprendizado pode colaborar para que respostas adequadas sejam dadas às pressões citadas acima, economizando no decorrer do processo o seu tempo dedicado ao ensino, e preservando, ao mesmo tempo, a qualidade da educação de nível superior. Essa deve ser uma das respostas aos problemas existentes. Quando se tem situações que exigem mudanças complexas, não se pode usar os mesmos conceitos (tecnologias, pedagogias, administração acadêmica) envolvidos nos problemas para se chegar às soluções necessárias. Não resolveremos os problemas existentes utilizando simplesmente apresentações eletrônicas que animem as aulas, juntando os alunos em auditórios com as mesmas aulas expositivas ou adotando mecanismos mais rígidos de controle de frequência.

\section{MUDANDO A CONVERSA DE APRENDIZADO COM BASE NOS BLOGS}

"A ecologia do conhecimento deve ser cultivada e fomentada, em vez de construída, organizada e comandada." George Siemens

O desafio está em como mudar a conversa nos ambientes de aprendizado e ensino com a utilização das tecnologias disponíveis. O bom uso dos blogs para o aprendizado implica em conversação. Como usá-los em associação com as ferramentas existentes na rede e os demais ambientes de colaboração? Como auxílio a essa tarefa, pode-se recorrer às comunidades de inquirição de Garrison (Figura 1) mostrada anteriormente. Nesse sentido, é mostrado a seguir um quadro de referência que pode auxiliar os professores a desenvolver o design de um ambiente colaborativo de aprendizado centrado nos blogs. É importante considerar que o envolvimento pleno e o alcance dos níveis mais 
altos do conhecimento, num ambiente de colaboração, é um processo evolutivo, em que uma vez vencida pelos alunos a sua barreira tecnológica, estes devem caminhar para a obtenção de um senso de comunidade, sentindo-se parte de um todo, no qual colaboram de forma efetiva para o alcance de objetivos comuns. Somente alcançado esse estágio, será possível o desenvolvimento de artefatos ou produtos de forma cooperativa, passíveis de serem validados pela comunidade na qual possam se inserir.

Quadro 3 - Estágios de mudança de conversa no aprendizado com o uso de blogs ( Baseado em BARLETT-BRAGG, 2011)

Primeiro Estágio : Estabelecendo o Ambiente da Conversa

Objetivo:

Estabelecer o início da prática de postagem, permitindo a familiarização com o novo modo de conversar e a apropriação das tecnologias necessárias ao usuário de blogs.

Conectar no ambiente de $b \log$.

Presença do professor:

- Evocar e motivar os alunos a se engajarem na conversa, através da disponibilização de um evento de disparo que crie motivação para a participação dos alunos na resolução de um problema.

- Prover questões ou tarefas mais estruturadas e simples como quebra-gelos, apresentações pessoais, guias para os alunos responderem ao evento e, com isso, conhecerem os mecanismos de participação nos blogs.

- Prover auxílio inicial aos alunos, facilitando o uso das tecnologias envolvidas (criação de seu $b \log$, colocação de postagens), com tutoriais específicos e uso de laboratório de informática.

- Avaliar mais a ação dos alunos (menos o conteúdo das postagens): suas reações ao uso das tecnologias (experiência anterior, dificuldades) e suas posturas nas conversas.

Presença do aluno:

- Criar, organizar e configurar o seu blog pessoal como o passo inicial para assumir a sua identidade na rede.

- Reconhecer os mecanismos do blog para disponibilizar suas postagens e comentários.

- Editar as páginas necessárias e incorporar diversas mídias (vídeos, áudios, widgets).

- Adquirir a motivação necessária para iniciar seu aprendizado (a partir do evento de disparo colocado pelo professor).

- Dar os primeiros passos na conversa a ser estabelecida através do uso de blogs.

- No início, há uma tendência de surgir uma conversa dirigida ao professor, com alguns alunos conseguindo expor receios e frustações com o processo, o que normalmente não fazem na sala de aula.

Papéis vivenciados:

Aluno : contactado, recém-chegado. 
Professor: convencedor, recepcionista, motivador.

Tecnologias suplementares:

- Moodle para as tarefas de aprendizado disponibilizadas pelo professor.

- Fórum do Moodle para suporte de dúvidas.

- Engenhos de pesquisa de multimídias (Google).

Segundo Estágio: Vencendo a Introspeção Inicial

Objetivo

Permitir o reconhecimento do ambiente com o início de um processo de sociabilização, através da consolidação do espaço individual de cada aluno.

Contribuir no ambiente de blog.

Presença do professor

- Disponibilizar atividades de aprendizado que iniciem o engajamento dos alunos para a continuação de suas postagens.

- Colocar questões ou tarefas ainda estruturadas (com o foco no próprio aluno) e que sirvam de guia para puxar as primeiras conversas (contribuições).

- Encorajar os alunos a compartilhar com colegas o endereço do seu blog e a primeira visita a este.

- Promover duplas de aprendizes com atividades de revisão mútua.

- Facilitar e acompanhar as atividades dos alunos, provendo auxílio rápido, inclusive com uso de laboratório.

Presença do aluno

- Reconhecer o ambiente e seus recursos, começando a prestar atenção na própria experiência e em suas emoções.

- Reconhecer o problema levantado pelo professor através do evento de disparo.

- O desafio de se apropriar da tecnologia ainda domina a experiência e, muitas vezes, impede uma participação mais significativa.

- Tem uma tendência de inserir comentários breves, reportando fatos, sem reconhecer os demais participantes do ambiente.

- Começa a desconhecer o professor (o autor das postagens) e a escrever para um leitor anônimo.

- Alguns ainda expressam emoções negativas.

Papéis vivenciados

Aluno : contribuidor, reconhecedor.

Professor: puxador, monitor.

Tecnologias suplementares:

- Agregadores de feeds para integração dos blogs dos alunos.

- Ambiente de bookmarking social.

Terceiro Estágio: Iniciando um Monólogo Reflexivo

Objetivo

Permitir o início de participação mais reflexiva dos alunos para aprofunda- 
mento do aprendizado, fazendo com que eles coloquem suas informações no blog considerando a existência de colegas que compõem a sua audiência (um grupo de envolvidos na mesma experiência de aprendizado).

Compartilhar no ambiente de $b \log$.

Presença do professor

- Disponibilizar, ao invés de questões estruturadas, sugestões de tópicos de trabalho, de forma que os alunos assumam responsabilidade nas suas postagens em função de suas próprias explorações.

- Promover grupos de aprendizes com atividades de resolução de problemas e reflexões, inclusive sobre o próprio aprendizado.

- Facilitar a ação dos alunos no espaço existente, acompanhar a sua atuação, suprir informações complementares, valorizando as melhores contribuições e elaborando resumos das discussões.

Presença do aluno

- Dar os primeiros passos num processo mais reflexivo, com maior consideração da experiência e entendimento do problema levantado.

- Pesquisar e disponibilizar, no seu blog, informações significativas necessárias à solução do problema levantado pelo professor.

- Reconhecer o tipo de postagem levantado no ambiente.

- Início do reconhecimento dos demais participantes, mesmo que as suas postagens não os considerem e sejam dirigidas para os próprios autores.

- São feitas postagens mais constantes e há tentativas de se situar na experiência.

- Podem ocorrer resistências às reflexões e ao aprendizado mais aprofundado.

- As emoções agora se relacionam com as atividades de aprendizado e não são direcionadas ao autor das postagens.

Papéis vivenciados

Aluno: compartilhador, prospector.

Professor: facilitador estrutural.

Tecnologias suplementares:

- Ferramentas de mapa mental ou conceitual.

Quarto Estágio: Propiciando Diálogos Reflexivos

Objetivo

Engajar os alunos na construção de um processo reflexivo mais amplo, que leve ao aprofundamento do aprendizado, fazendo com que adquiram um senso de comunidade na co-construção de conhecimentos necessários e auxiliem-se mutuamente no alcance de objetivos acordados em comum.

Colaborar no ambiente de blog.

Presença do professor

- Oferecer somente pistas de atividades de aprendizado que estimulem os próprios alunos a criar suas concepções através da criação de um senso de comunidade, se envolvendo com seus pares nos tópicos e assuntos a serem trabalhados.

- Dividir com os alunos a responsabilidade dos conteúdos trabalhados no 
ambiente.

- Definir os papéis que os alunos possam assumir no ambiente de colaboração criado, envolvendo toda a turma de alunos.

- Encorajar a participação em rede e criar as condições para os alunos com dificuldades assumirem a auto-direção do seu próprio processo de aprendizado.

Presença do aluno

- Adquirir uma voz ou estilo próprio de escrita no novo modo de conversação, em vez da inserção de simples relatos superficiais.

- Co-construir conhecimentos ou concepções que sejam a solução do problema levantado.

- Exercer os papéis necessários no ambiente de colaboração existente.

- Ler os blogs dos colegas, fazer comentários nestes, compartilhar sua experiência e opiniões numa postura de colaboração.

- Reconhecer as dificuldades e necessidades dos seus pares na realização das atividades existentes e assisti-los nas suas dificuldades.

- Consideração crescente de seu estilo de expressão, da audiência alvo e do papel assumido no ambiente.

- Reconhecimento de seu próprio aprendizado.

Papéis vivenciados

Aluno : colaborador, assistente.

Professor: facilitador social.

Tecnologias suplementares:

- Microblog para auxiliar o contato entre alunos.

- Rede social integrada com o uso de blogs.

Quinto Estágio: Validando a Discussão

Objetivo

Favorecer a possibilidade da utilização dos conhecimentos construídos para o alcance de soluções que sejam validadas por uma comunidade de parceiros comprometidos numa prática de interesse comum.

Cooperar no ambiente de blog.

Presença do professor e aluno

- Agir como um parceiro na definição e no desenvolvimento de uma prática a ser trabalhada em função das soluções encontradas anteriormente.

- Fomentar o desenvolvimento e a participação dos alunos em projetos de interesse comum.

- Facilitar o envolvimento de parceiros externos, que se envolvam como interessados e especialistas em tópicos de relevância para a prática a ser desenvolvida.

- Avaliar a adequação dos conhecimentos construídos nos ciclos anteriores em soluções práticas demandadas por pessoas ou organizações na sociedade.

- Auxiliar a identificação de blogs externos que sejam importantes na prática a ser trabalhada.

- Vivenciar uma blogosfera de parceiros envolvidos em experiências comuns. 
Papéis vivenciados

Aluno e professor: cooperadores, parceiros, desafiadores, agentes de inovação, consultores, agregadores.

Tecnologias suplementares:

- Wiki para organizar o conhecimento construído de forma coletiva.

- Ferramenta de curadoria para expor os conteúdos relevantes e os produzidos na experiência vivenciada.

- Ferramenta para gestão dos projetos colaborativos.

Com esse conjunto de estágios evolutivos e crescentes pode-se viabilizar a mudança de conversa no processo de ensino e aprendizado, em que a participação poderá evoluir através dos novos papéis exercidos por alunos e professores. Urge a criação de ambientes de aprendizado que permitam, aos professores, facilitar uma prática na qual os alunos assumam habilidades de pensamento mais avançado, sustentando nos blogs discussões de forma a auto-dirigir suas reflexões, análises e sínteses para o alcance de resultados desejados. Para que isso aconteça, é necessário elaborar o design de ambientes em que esses papéis possam ser experimentados e avaliados.

\section{CONSIDERAÇÕES FINAIS}

"O professor deve orientar o seu trabalho não no desenvolvimento de ontem do aluno, mas no de amanhã." Lev Vygotsky

Envolver-se nas mudanças necessárias à educação no mundo de hoje é desafio para toda a sociedade. No caso das universidades, professores, funcionários, dirigentes e os próprios alunos têm como dever congregar seus esforços nesse sentido. Em função disso, deve-se apoiar e participar efetivamente de programas como os da Rede de Desenvolvimento de Práticas de Ensino Superior - GIZ, através da qual a UFMG pretende canalizar seus esforços e recursos visando a valorização da ação docente e a criação de condições para que a inovação floresça nas aulas de seus diversos cursos. Quanto mais professores se dispuserem a experimentar novas abordagens e os novos meios disponíveis de mediação com seus alunos, maior será o ganho de todos. Já está mais do que comprovado que a presença do professor, através do ensino, é um dos fatores mais significativos para determinar a satisfação dos alunos, a percepção destes de seu aprendizado e até a criação de seu senso de comunidade. Essa presença certamente será mais significativa com a utilização de ambientes colaborativos de aprendizado. 
Conversas interativas são um fator chave no aprendizado mais aprofundado e só podem ocorrer quando o professor exercer o seu papel nesse contexto. Não somente expor e apresentar seus conteúdos, mas também facilitar e promover os alunos nos caminhos que estes devem cursar para que possam assumir o seu próprio aprendizado. A viabilização plena dos papéis de expositor e facilitador somente será possível a partir do reconhecimento pelos professores e suas instituições da necessidade do design dos ambientes de aprendizado, a criação do espaço adequado para que seja viabilizado um novo tipo de conversa necessária ao aprendizado. Certamente, quando as pessoas se dispuserem a se envolver nessa empreitada, muitas dificuldades existirão, uma vez que existem muitas questões que estão à procura de respostas nessa área. Acredita-se que somente plantando sementes de inovação e cuidando de experimentos na realidade, com troca de experiência e participação em redes de colaboração, pode-se achar algumas dessas respostas.

Quadro 4 - Questões que necessitam ainda de uma maior investigação

\section{Questões ainda à procura de respostas}

Como tornar nossas aulas compatíveis com a sociedade de hoje, que cada vez mais valoriza o digital e o social no nosso envolvimento com o conhecimento?

Como sensibilizar um professor de ensino superior para a necessidade de mudança de seu modo de conversar com os alunos?

É possível usar blogs na prática de ensino e aprendizado em todos os tipos de disciplinas da Universidade?

É possível criar um ambiente de aprendizado de qualidade nas disciplinas pelas quais passa uma massa crescente de alunos?

Que importância tem a criação, pelos próprios professores, de uma rede de colaboração que favoreça a inovação nas aulas?

\section{REFERÊNCIAS}

BARTLETT-BRAGG, A. Blogging to learn. The Knowledge Tree. An e-Journal of Flexible Learning in VET. Disponível em http:/ / knowledgetree.flexiblelearning.net.au/edition04/html/blogging_to_learn_intr o.html. Acesso em 17/09/2011.

BRYAN, A.; Levine. A.. Web 2.0 Storytelling: Emergence of a New Genre. EDUCAUSE Review, vol. 43, N. 6, nov/dez 2008.

DU, H. S., Wagner, C.. Learning with Weblogs: An Empirical Investigation. Proceedings of the 38th Hawaii International Conference on System Sciences, pg. $7 \mathrm{~b}$ (2005). 
CONOLE, G.. Review of pedagogical models and frameworks. Disponível em http:/ / www.slideshare.net/grainne/ pedagogical-models-and-their-use-in-elearning20100304 acesso em 14/10/2011

ELGORT, I.. E-learning adoption: Bridging the chasm. 22nd Annual Conference of the Australasian Society for Computers in Learning in Tertiary Education (ASCILITE). Brisbane, Australia, v.1, p. $181 \quad$ - 185, 2005. Disponível em http://www.ascilite.org.au/conferences/brisbane05/blogs/proceedings/20_Elgort.p df. Acesso em 17/09/2011

GARRISON, D. R. Online community of inquiry review: Social, cognitive, and teaching presence issues. Journal of Asynchronous Learning Networks, 11(1), 61-72, 2007. Disponível em http://people.ucalgary.ca/ nvaughan/coiissues.pdf acesso em $17 / 09 / 2011$

GIZ - Rede de Desenvolvimento de Práticas de Ensino Superior- Universidade Federal de Minas Gerais. Disponível em http:// giz.lcc.ufmg.br/giz09 , acesso em 04/12/2011

GOODYEAR, P., Teaching, technology and educational design, Relatório final para Australian Learning and Teaching Council. Disponível em http://www.altcexchange.edu.au/teachingdesign. Acesso em 12/03/2011.

HALIC, O., PAULUS, T., \& SPENCE, M.. To blog or not to blog: Student perceptions of blog effectiveness for learning in a college-level course. The Internet and Higher Education, 13(4), p. 206-213, 2010.

LAKKALA, M.. The pedagogical design of technology enhanced collaborative learning. eLearning Papers, June 20, 2007, Disponível em http://www.elearningeuropa.info/files/media/media13028.pdf

Acesso em 17/09/2011.

LAURILLARD, D. (2002). Rethinking university teaching : a conversational framework for the effective use of learning technologies (2nd ed.). RoutledgeFalmer.

RIBEIRO, A.M.; COELHO, M.L.. O uso das novas tecnologias e as formas de aprendizagem: Análise de uma experiência, Seminário Nacional da $A B E D$, abril de 2006, http://www.abed.org.br/seminario2006/pdf/tc029.pdf. Acesso em 23/11/2011.

SALMON, G. E-tivities: the key to active only learning. Sterling, VA: Stylus Publishing, 2002.

SIEMENS, G.. Knowing Knowledge. Lulu.com, 2006. livro disponível de forma livre

http://www.elearnspace.org/KnowingKnowledLoge_wRes.pdf , acesso em $17 / 09 / 2011$

WEELER, S. Blog Learning with 'e's. Disponível em http://stevewheeler.blogspot.com/. Acesso em 17/09/2011.

WILSON S., Liber Ol., Johnson M., Beauvoir P., Sharples P., Milligan C.. Personal Learning Environments: Challenging the dominant design of educational systems, 19/09/2006, http://hdl.handle.net/1820/727 acesso em 12/12/2011

VYGOTSKY, L. S. A formação social da mente. 6. ed. São Paulo, SP, Martins Fontes, 1998. 


\section{Bloglossário}

$\boldsymbol{B} \log (w e \boldsymbol{b}+\log )$ : local na rede (website) onde são disponibilizadas, por um autor, postagens multimídia em ordem cronológica inversa, as quais podem receber comentários de seus leitores. Inicialmente, era visto como um meio online para a publicação de um diário pessoal. Hoje já ultrapassou em muito essa visão.

Blogar: atividade de exploração de blogs: criação, leitura, atualização, organização, configuração, compartilhamento, integração com leitores, outros blogs, aplicações (widget ou gadgets).

Blogueiro: pessoa que bloga, normalmente responsável por um blog pessoal ou profissional.

Blogosfera: conjunto de blogs e suas interconexões, normalmente considerada como uma comunidade que envolve os interessados num assunto específico (de interesse de cada um dos blogs participantes).

Blogfólio: coleção de blogs ou portfolio criado na forma de um blog, que registra a experiência profissional ou escolar de uma pessoa.

Feed: formato de dados padronizado (RSS, Atom) usado para prover a seus usuários as atualizações dos conteúdos dos sites de seu interesse, recebendo-os de forma agregada, sem necessidade de visitá-los individualmente.

Microblog: ambiente do tipo blog, no qual as postagens são limitadas a poucos caracteres alfa-numéricos, permitindo a criação de comunidades de seguidos e seguidores.

Share (Compartilhamento): segmento de código em linguagem HTML que permite que uma mídia (vídeo do Youtube) ou uma pequena aplicação (widget de chat) seja incorporada num ambiente como um blog e utilizada diretamente neste.

Widget ou Gadget: pequena aplicação de software, módulo, ferramenta ou serviço que pode ser agregado a um ambiente maior.

Wiki: tipo de software social para criação e alteração fácil de páginas integradas, permitindo a sua realização de forma coletiva (exemplo: enciclopédia Wikipedia). 